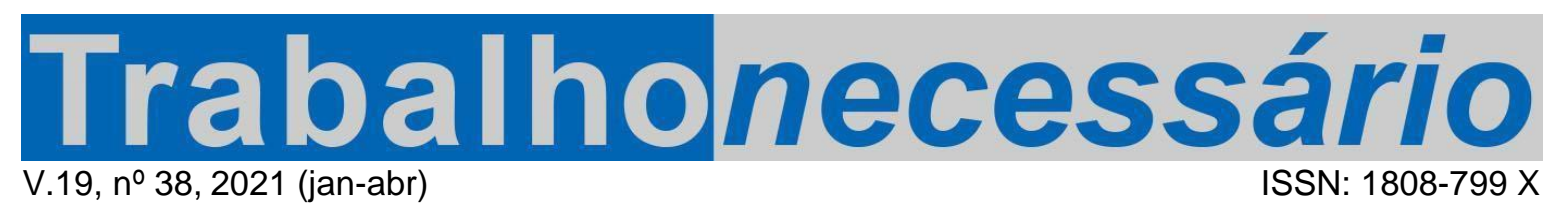

\title{
A LUTA CONTRA A OPRESSÃO DA MULHER EM ALEXANDRA KOLLONTAI ${ }^{1}$
}

\author{
Denise Santana Maia ${ }^{2}$ \\ Cláudio Félix dos Santos ${ }^{3}$
}

\begin{abstract}
Resumo
O presente trabalho tem por objetivo discorrer acerca de aspectos do pensamento e da vida de Alexandra Kollontai acerca da luta contra a opressão feminina em seu processo de formação política. O referido estudo tem como aporte as seguintes obras: "A Nova mulher e a Moral Sexual" e "Autobiografia de uma mulher emancipada". Discutimos nesta ocasião os obstáculos encontrados pela autora na luta pela construção do socialismo, explorando as seguintes questões: a situação da mulher na Rússia e as possibilidades de uma nova moral sexual; a concepção de amor e família para a sociedade socialista em construção.
\end{abstract}

Palavras-chave: Alexandra Kollontai. Mulher. Moral sexual. Comunismo.

\section{LA LUCHA CONTRA LA OPRESIÓN DE LAS MUJERES EN ALEXANDRA KOLLONTAI}

\section{Resumen}

El presente trabajo tiene como objetivo analizar, a partir del pensamiento de la autora Rusa Alexandra Kollontai, algunos desafíos que encontró en la lucha contra la opresión femenina en su proceso de formación política. Este estudio aborda la análisis de su pensamiento a partir de los siguientes textos: "La nueva mujer y la moral sexual" y "Autobiografía de una mujer emancipada". En ese texto, discutimos los obstáculos encontrados por la autora en la lucha por la construcción del socialismo, explorando los siguientes temas: la situación de la mujer en Rusia y las posibilidades de una nueva moral sexual; la concepción del amor y la familia para la sociedad socialista en construcción.

Palabras-claves: Alexandra Kollontai. Mujer. Moralidad sexual. Comunismo.

\section{THE FIGHT AGAINST OPPRESSION OF WOMEN IN ALEXANDRA KOLLONTAI}

\begin{abstract}
This work aims to analyze, based on the thoughts of the Russian writer Alexandra Kollontai, the challenges she faced in her fight against female oppression during her political formation. This study comprises the analysis of her thoughts based on the following works: New Woman and Sexual Morality and The Autobiography of a Sexually Emancipated Communist Woman. We discuss the obstacles faced by Kollontai during her fight for socialism, delving into the situation of women in Russia and the possibilities of a new sexual morality, and the conception of love and family for the society in construction.
\end{abstract}

Keywords: Alexandra Kollontai. Woman. Sexual morality. Communism.

\footnotetext{
1 Artigo recebido em 22/12/2020. Primeira avaliação em 12/01/2021. Segunda avaliação em 14/01/2021. Aprovado em 25/01/2021. Publicado em 25/02/2021

DOI: https://doi.org/10.22409/tn.v19i38.47776

${ }^{2}$ Denise Santana Maia: Mestrado em Memória: Linguagem e Sociedade/UESB.

E-mail: ise.direito@gmail.com.; Lattes: http://lattes.cnpq.br/6844284111505847.

ORCID: https://orcid.org/0000- 0003-1022-2312

${ }^{3}$ Cláudio Félix dos Santos: Universidade Estadual do Sudoeste da Bahia; Doutor em Educação UFBA; Pesquisador do Museu Pedagógico Padre Palmeira (UESB) e do Grupo de Estudos Marxistas em Educação. E-mail: cláudio.felix@uesb.edu.br; Lattes: http://lattes.cnpq.br/7594684135461900; ORCID: https://orcid.org/0000-0003-0545-1102
} 


\section{Introdução}

A luta contra a opressão da mulher tomou novos rumos com a revolução Russa de 1917 e a elaboração de reflexões e orientação política advindas de militantes e intelectuais que se debruçaram sobre essa questão. Dentre essas pessoas encontrava-se Alexandra Kollontai.

Há pesquisas e estudos diversos sobre Kollontai, contudo, o texto que aqui apresentamos $^{4}$ constitui uma reflexão a partir das memórias escritas por uma revolucionária comunista acerca de antigos problemas da sociedade patriarcal e seu enfrentamento no percurso da Revolução Russa entre 1917 e 1926 (ano em que escreveu sua autobiografia).

Nas "trilhas" deixadas por Kollontai, entendemos que a busca por materializar novas relações sociais tinha na luta pela socialização dos grandes meios de produção sua meta maior. Contudo, havia neste processo determinados impasses, como a necessidade de voltar os olhares e ações para a luta contra a opressão da mulher. Isso se expressava nos conteúdos e formas de submissão feminina por meio da moral sexual e tantas tentativas de submissão que Alexandra Kollontai combateu fortemente.

Do mesmo modo, as experiências e visões sobre o amor e a família cristalizavam memórias e atitudes que precisavam ser superadas para que o novo homem e a nova mulher pudessem nascer a partir de um acontecimento radical na história da humanidade e nas lutas do proletariado: a Revolução de outubro de 1917 na Rússia.

Tomando como "fio condutor" as experiências relatadas em seu livro intitulado "Autobiografia de uma mulher emancipada", escrito em 1926 e publicado em 1946; bem como no livro "A nova mulher e a moral sexual", publicado em 1918, percorremos uma pequena parte de sua trajetória de militância articulando sua autobiografia com alguns materiais produzidos por esta autora em relação à condição da mulher no enfrentamento da luta contra a exploração, a opressão (de classe e gênero) e a construção do socialismo.

\footnotetext{
${ }^{4}$ Esse artigo é baseado na dissertação de Mestrado defendida por Denise Maia no Programa de PósGraduação em Memória: Linguagem e Sociedade da Universidade Estadual do Sudoeste da Bahia. A dissertação intitula-se: Alexandra Kollontai: Memória, reflexões e lutas pela libertação da mulher.
} 


\section{Alexandra Kollontai: Formação e trajetória revolucionária}

No ano de 1872, na cidade de San Petersburgo, nasce Alexandra M. Domontovitch. O sobrenome Kollontai veio de seu ex-marido.

Oriunda de uma família de proprietários nobres, sendo seu pai um general russo de origem ucraniana e sua mãe finlandesa de origem campesina, Alexandra passou sua infância na cidade de San Petersburgo nas últimas décadas do século passado. Segundo Kollontai (1978), morar naquela cidade significava viver em um dos centros industriais mais importantes da Rússia na qual o movimento operário se mostrou muito pujante.

Seus pais optaram por realizar sua educação no modelo aristocrata, contratando professores particulares para o ensino em casa. Em seu percurso de apropriação da cultura, a jovem sempre demonstrou apreço pela leitura e pelo conhecimento. Sob influência de uma de suas professoras mais queridas, em sua adolescência chegou a se inserir em um grupo de jovens revolucionários de São Petersburgo demonstrando forte atitude e pensamento crítico que havia adquirido antes mesmo de tomar contato com o marxismo (KOLLONTAI, 1978).

Apesar do receio de seus pais, Kollontai se envolvia cada vez mais com a política e os estudos sobre a sociedade russa, em especial a situação da mulher. Em uma das passagens de sua autobiografia ela relata:

A sociedade russa tinha características de patriarcado. $O$ homem, o pai, era o agente ativo que decidia e controlava, desde os menores, como a família, até os maiores como o aparato estatal e econômico. A mulher estava relegada a um segundo posto. No campo, seu trabalho não era tão importante quanto do homem (a mão de obra era abundante) e sua missão consistia na criação dos filhos e no cuidado da casa; as pequenas tarefas artesanais ou agrícolas que desempenhavam não tinham um valor fundamental. A mulher não havia se incorporado ainda ao trabalho industrial. Em um país onde existia tanta miséria e a mão de obra masculina era excedente e baratíssima, desvalorizava-se o trabalho feminino, a mulher operária foi socialmente quase inexistente, e sua incorporação aos movimentos sociais emancipadores foi mais tardia que em outros países europeus (KOLLONTAI, 1978, p. 22. Tradução nossa).

Nessa passagem, Alexandra Kollontai anuncia um conceito que bem definia os limites de liberdade das mulheres: a presença do patriarcado. Sobre o referido conceito, Misa Boito explica: 
O patriarcado - como forma de organização social na qual é exercido o poder do homem sobre a mulher - não é exclusivo do capitalismo. Ele surge na história da humanidade juntamente com a propriedade privada, que coloca a questão da transmissão da riqueza, da herança e da definição da paternidade. Antes do surgimento da propriedade privada, a sociedade se organizava em torno da figura da mãe. Com a família monogâmica, quando a mulher é entregue "ao poder do homem", como explicou Engels, nasce o germe do Estado patriarcal. Ao modo de produção capitalista corresponde o estado burguês, no qual se mantém o patriarcado - e não poderia ser diferente, pois a questão da propriedade privada e sua transmissão seguem colocadas (BOITO, 2016, p. 15).

Portanto, segundo a autora, o patriarcado se articula ao surgimento da propriedade privada. O argumento de Boito (2016) nos leva a concluir que o movimento das mulheres contra a opressão deve ser pensado a partir da história, das formas de produção da existência humana, que tem como marca a exploração dos trabalhadores e trabalhadoras. Esse fato produz, de modo particular, comportamentos e visões de mundo que impõem à mulher a condição de submissão ao homem. Portanto, mais do que uma questão de luta pela emancipação feminina, ou de instigar o conflito de homem versus mulher, Boito (idem), a partir das reflexões de Engels, entende ser necessário compreender e lutar contra a opressão da mulher no seio da totalidade das relações sociais de exploração e dominação, que têm na propriedade privada a sua gênese.

Na adolescência, a jovem Alexandra morou na Finlândia e estudou a história de luta daquele povo contra a aristocracia czarista (KOLLONTAI, 1978). Desde então, foram muitos os eventos dos quais a autora participou ao longo de sua trajetória na luta pela revolução socialista que culminou com a vitória do proletariado em outubro de 1917.

Em meio ao cenário de Revolução, as mulheres trabalhadoras também foram amparadas por novos direitos como o divórcio, conquistado com o decreto de 18 de dezembro de 1917. Essa legislação, segundo a própria Alexandra, livrou muitas mulheres da permanência em situações de violência doméstica.

Kollontai assumiu tarefas de comando no governo e no partido no processo revolucionário pós-1917. Esta nova responsabilidade ligou Kollontai a atribuições importantes como o cargo de Comissária do Povo para o Bem-Estar Social. Na sua gestão instituiu a central de proteção à maternidade e ao recém-nascido. $O$ referido projeto de lei se firmou em janeiro de 1918, ocasião na qual Kollontai transformara todas as maternidades em residências gratuitas para atender às mães e seus 
respectivos filhos. Segundo a autora, essa medida tornaria a proteção à maternidade um instituto completamente estatal e seguro para as mulheres (KOLLONTAI, 1978).

Em 1926, como Comissária de Saúde do Governo Soviético, comandou importantes missões diplomáticas na Noruega, Suécia, México e Finlândia (KOLLONTAI, 2011).

Todavia, é recorrente em sua autobiografia o registro dos vários desafios encontrados no sentido de pautar questões específicas das mulheres no partido e no governo. Esse fato exigia que ela continuasse formulando reflexões e desenvolvendo ações na luta contra a opressão da mulher. A seguir, passamos a apresentar algumas reflexões sobre família, o amor, e a relação homem e mulher na transição ao socialismo na perspectiva daquela militante.

\section{O amor-camaradagem e o matrimônio na transição a uma sociedade emancipada}

Kollontai (1978) afirmou em sua autobiografia que enquanto esteve casada com seu companheiro, pai de seu único filho, o matrimônio the despertou certa angústia por se sentir presa e impedida de se empenhar com mais vigor aos movimentos políticos e à luta das mulheres. Segundo a autora, o matrimônio the tirava a atenção sobre o que realmente importava: a condição social das mulheres trabalhadoras e a situação da Rússia.

Ela entendia que todas as relações humanas deveriam fundamentar-se no amor. Contudo, constatava que o matrimônio não se baseava tão somente neste princípio, mas, sobretudo, em uma ideia de posse do homem em relação à mulher. Esta seria uma das primeiras reflexões feitas pela autora no sentido de pensar as relações de gênero na ótica marxista. Na sua crítica ao matrimônio ela afirma:

[...] O matrimônio legal está fundado em dois princípios igualmente falsos: a indissolubilidade, por um lado, e o conceito de propriedade, da posse absoluta de um dos cônjuges pelo outro. A indissolubilidade do matrimônio legal está baseada numa concepção contrária a toda ciência psicológica; na invariabilidade da psicologia humana no transcurso de uma longa vida. [...] O segundo fator que envenena o matrimônio legal é a ideia de propriedade, e posse absoluta de um dos cônjuges pelo outro" (KOLLONTAl, 2011, p. 2830). 
Fruto das condições objetivas das relações de exploração e dominação e dos modos de produção material e espiritual da vida, o universo feminino foi se limitando ao âmbito da vida privada: família, cuidados com os filhos, e as atividades domésticas; bem como a prostituição para outras parcelas de mulheres. Enquanto isto, os homens dedicavam-se à vida pública, aos interesses econômicos e políticos. Segundo a autora, a solução para a construção de relações de gênero livres estaria na promoção e na prática de determinados princípios, especialmente os da camaradagem e da solidariedade, como pontos de partida no esforço de transição para a construção de uma sociedade que se pretendia socialista.

Segundo ela, a camaradagem e a solidariedade na relação homem e mulher são da maior importância para a construção da sociedade socialista. Ela compreendia que a construção de uma sociedade socialista como transição ao comunismo, e, portanto, ao modo de produção da vida com a inexistência da propriedade privada dos grandes meios de produção passa, concomitantemente, pelo processo de criação de novas relações sociais e pessoais entre os indivíduos. Nas palavras de Alexandra Kollontai:

A nova sociedade comunista será edificada sobre o princípio da camaradagem e da solidariedade. Mas o que é a solidariedade? Não somente devemos entender por solidariedade a consciência da comunidade de interesses; constituem a solidariedade, também, os laços sentimentais e espirituais estabelecidos entre os membros da mesma coletividade trabalhadora. $O$ regime social edificado sobre 0 princípio da solidariedade e da colaboração exige que a sociedade em questão possua, desenvolvida em alto grau, a capacidade do potencial de amor, isto é, a capacidade para a sensação de simpatia. [...] a ideologia proletária procura educar e reforçar em cada um dos seus membros da classe operária sentimentos de simpatia diante dos sofrimentos, das necessidades de seus camaradas de classe. A ideologia proletária tende também, a compreender as aspirações dos demais e desenvolver a consciência de sua união com os outros membros da coletividade (KOLLONTAI, 2011, p. 121).

O projeto de construção de uma sociedade comunista se daria articulada a uma transformação da "psicologia humana"5, inspirando homens e mulheres a trabalharem em benefício das necessidades da coletividade, do grupo. (KOLLONTAI, 2011). Segundo ela, este não é um princípio presente na ideologia e

${ }^{5} \mathrm{~A}$ autora utiliza o termo "psicologia humana" para se referir aos fundamentos psicológicos dos comportamentos de homens e mulheres, que são formados/construídos socialmente, e, consequentemente, mutáveis ao longo do tempo. O referido termo é usado especialmente em sua obra "A mulher e a moral sexual". A autora o usa especialmente para tratar da questão sexual entre homens e mulheres. 
na família burguesa, visto que a burguesia defende fortemente a proteção da unidade familiar endurecida por papéis e funções sociais pré-determinados, isolando e repreendendo homens e mulheres sob uma moral sexual específica. Portanto, não há liberdade entre os cônjuges, nem entre o restante da família que compõe essa mesma estrutura. Existe, de fato, uma naturalização das relações de opressão de homens sobre as mulheres, como se isso fizesse parte da natureza humana.

Portanto, para superar essas determinações, o exercício da solidariedade e do respeito entre os camaradas são sentimentos gerados no amor, enquanto capacidade de amar, em seu sentido mais amplo. O amor é um sentimento orgânico que por natureza une os indivíduos. O amor se constitui enquanto meio para o desenvolvimento de uma solidariedade coletiva (KOLLONTAI, 2011).

Ao aprofundar suas reflexões sobre o amor, Alexandra Kollontai recorre à história para buscar o desenvolvimento das formas e dos conteúdos do amor. Segundo ela,

Cada época da história possui seu próprio ideal de amor. [...] cada classe, em seu próprio interesse, atribui à noção moral de amor um conteúdo determinado. Cada grau da civilização traz à humanidade sensações morais e intelectuais mais ricas em matizes, que cobrem o amor com um colorido diverso. A evolução no desenvolvimento da economia e nos costumes sociais foi acompanhada de novas modificações no conceito de amor. Alguns matizes desses sentimentos se reforçavam, mas os outros caracteres diminuíam ou desapareciam totalmente. O amor, no transcurso dos séculos de existência da sociedade humana, evoluiu de um simples instinto biológico (instinto de reprodução, comum a todos os seres vivos, superiores ou inferiores, divididos em dois sexos) e se enriqueceu sem cessar com novas sensações, até converter-se num sentimento muito complexo. O amor deixou de ser um fenômeno biológico para converter-se num fator social e psicológico (KOLLONTAI, 2011, p. 122-123).

A partir do entendimento do amor enquanto sentimento que se expressa de infinitas maneiras, o ideal de amor para além da perspectiva romântico-burguesa pode ser assim entendido:

O exclusivismo e a absorção do sentimento de amor não podem constituir, do ponto de vista da ideologia proletária, o ideal de amor determinante nas relações entre os sexos. Ao contrário, 0 proletariado, ao tomar conhecimento da multiplicidade do amor, não se assusta absolutamente com esta descoberta, nem tampouco experimenta indignação moral como aparenta a hipocrisia burguesa. O proletariado trata, ao contrário, de dar a este fenômeno (que é resultado de complicadas causas oficiais) uma direção que sirva a 
seus fins de classe, no momento da luta e da edificação da sociedade comunista. Estará, por acaso, a multiplicidade do amor em contradição com os interesses do proletariado? Ao contrário, esta multiplicidade no sentimento do amor facilita o triunfo do ideal de amor nas relações entre os sexos, que já se formam e cristalizam no seio da classe operária: o amor-camaradagem (KOLLONTAI, 2011, p. 127).

Podemos observar no excerto uma profunda crítica materialista histórica às concepções burguesas de amor e relação entre homem e mulher. O esforço de construção do "amor-camaradagem", o amor entendido desde o ponto de vista de relações humanas não mediadas por relações de exploração e opressão, estaria baseado em valores que superem a mesquinharia burguesa, distinguindo-se completamente das noções de amor estabelecidas em outras épocas da civilização. Importante destacar que Kollontai não despreza o amor romântico. Pelo contrário, prepara o reconhecimento do sentimento de amor como força social e psíquica que liberta e não aprisiona o ser humano (KOLLONTAI, 2011).

Por sua vez, na visão de mundo burguesa, a família e o amor entre um casal apenas se poderiam estabelecer através do matrimônio, o qual representou um dos alicerces da moral sexual burguesa. Neste sentido, afirma Kollontai:

Para o sucesso das tarefas do proletariado, é indiferente que o amor tome a forma de uma união estável ou que não tenha mais importância que uma união passageira. A ideologia da classe operária não pode fixar limites formais ao amor. Ao contrário, esta ideologia começa a sentir inquietação pelo conteúdo do amor, pelos laços de sentimentos e emoções que unem os dois sexos; por isso, neste sentido, a ideologia proletária tem que enfrentar a luxúria, a satisfação única dos desejos carnais pela prostituição, a transformação do ato sexual num fim em si mesmo, que faz dele um prazer fácil etc., mais implacavelmente que o fazia a moral burguesa. A luxúria está em contradição com os interesses da classe operária. Em primeiro lugar, este amor supõe inevitavelmente os excessos e o esgotamento físico, que contribuem para diminuir a reserva de energia da humanidade. Em segundo lugar empobrece a alma porque impede o desenvolvimento, entre os seres humanos, de laços psíquicos e de sensações de simpatia. Em terceiro lugar, este amor tem por base a desigualdade de direitos entre os sexos nas relações sexuais; ou seja, está baseado na dependência da mulher em relação ao homem, na vaidade ou insensibilidade do homem, o que afoga necessariamente toda a possibilidade de experimentar um sentimento de camaradagem. Em troca, a ação exercida sobre os seres humanos pelo amor espiritual é completamente distinta (KOLLONTAI, 2011, p. 128). 
Portanto, ao identificar a concepção de amor na perspectiva burguesa e diferenciá-la da perspectiva socialista, a autora destaca que para a burguesia o amor exige que o homem ou a mulher só enxergue e se vanglorie das qualidades de doação, delicadeza, sensibilidade de ser útil apenas ao eleito ou à eleita e, nesse sentido, ao núcleo familiar como algo isolado da sociedade. Por sua vez, numa perspectiva socialista, se espera que essas qualidades despertem, desenvolvam e eduquem homens e mulheres de modo que o sentido do amor se manifeste não apenas dentro da relação amorosa, mas sobre toda a comunidade.

Podemos perceber uma profunda preocupação da dirigente revolucionária com as relações entre homens e mulheres no campo privado em articulação com as determinações sociais gerais. Além disso, destacava o quanto de obstáculos deveriam ser enfrentados para construir comportamentos e visões de mundo que alcançassem formas não-alienadas de convivência no desenvolvimento de sentimentos que deveriam pautar essas relações. Essas relações teriam seus fundamentos no amor-camaradagem, "no reconhecimento dos direitos recíprocos na arte de respeitar, inclusive no amor, a personalidade do outro, num firme apoio mútuo e na comunidade de aspirações coletivas" (KOLLONTAI, 2011, p. 129).

Segundo a perspectiva da autora, seria necessária uma transformação no modo de se conceber o amor entre homens e mulheres. A transição para uma sociedade socialista implica, reciprocamente, a passagem para a vivência de uma nova forma de amor e de sua inteira expressão em comunidade, com bases em laços de empatia entre os membros da nova sociedade que, na expectativa de Kollontai, desenvolveria e fortaleceria as relações entre camaradas. Desse modo,

a capacidade para amar será muito maior, e o amor-camaradagem se converterá no estimulante papel que na sociedade burguesa estava reservado ao princípio de concorrência e ao egoísmo. O coletivismo do espírito e da vontade triunfarão sobre o individualismo que se bastava a si mesmo. Desaparecerá o frio da solidão moral, do qual no regime burguês os homens tentavam escapar, refugiandose no amor ou no matrimônio; os homens ficarão unidos por inúmeros laços sentimentais e psíquicos. Seus sentimentos se modificarão no sentido do interesse cada vez maior pela coisa pública. Desaparecerão sem deixar o menor rastro a desigualdade entre os sexos e todas as formas de dependência da mulher em relação ao homem (KOLLONTAI, 2011, p. 129).

Kollontai deixou claro que a superação da sociedade e da moral burguesas são fundamentais para a superação da opressão feminina. A experiência da 
Revolucionária Russa na luta pela construção do socialismo trazia novas possibilidades de transformação da realidade.

Os ventos de mudança que sopravam por aqueles territórios no ano de 1918, primeiro ano da revolução Russa, inspiravam Alexandra Kollontai a afirmar que no futuro seria possível:

Nesta nova sociedade, coletivista por seu espírito e suas emoções,
caracterizada pela união feliz, por relações fraternais entre os
membros da coletividade trabalhadora e criadora, o amor ocupará
um lugar de honra, como sentimento capaz de enriquecer a
felicidade humana. Como se transfigurará? Nem a fantasia mais
criadora é capaz de imaginá-lo. Só é indiscutível que, quanto mais
unida estiver a humanidade pelos laços duradouros da solidariedade,
tanto mais intimamente unida estará em todos os aspectos da vida,
da criação ou das relações mútuas [...] Neste mundo novo, a forma
reconhecida, normal e desejada das relações entre os sexos estará
fundamentada puramente na atração sadia, livre e natural (sem
perversões, nem excessos) dos sexos; as relações sexuais dos
homens na nova sociedade estarão determinadas pelo novo amor
(KOLLONTAl, 2011, p. 130).

A autora defendia que o caráter coletivista desta nova sociedade traria não apenas melhores condições materiais de vida, mas um equilíbrio nas relações sexuais, muitas destas marcadas pela prostituição, violência de todas as ordens, submissão e tantas outras manifestações de opressão da mulher.

Kollontai entendia que três princípios fundamentariam as relações de gênero, quais sejam: a) igualdade entre os sexos (eliminando de vez a submissão da mulher nas relações amorosas); b) reconhecimento mútuo e recíproco dos direitos das mulheres (sem o exercício do sentimento de posse); c) sensibilidade fraternal (o respeito à personalidade do outro, às particularidades da sexualidade feminina e masculina) (KOLLONTAI, 2011).

Desta maneira, poderia emergir um novo sentido ao amor:

A classe ascendente da humanidade criará motivos de beleza, força e brilho até agora desconhecidos. [...] o amor muda de aspecto e se transforma, inevitavelmente, uma vez que se transformam as fases econômicas e culturais da sociedade. Se conseguirmos que, das relações de amor, desapareça o cego, o exigente e absorvente sentimento passional; se desaparece, também, o sentimento de propriedade, tanto quanto o desejo egoísta de unir-se para sempre ao ser amado; se conseguirmos que desapareça a vaidade do homem, e que a mulher não renuncie criminosamente ao seu eu, não há dúvida de que, com o desaparecimento de todos esses sentimentos, desenvolvam-se outros elementos preciosos para o 
amor. [...] A tarefa da ideologia proletária não é, pois, separar das suas relações sociais o amor, mas dar-lhe um novo colorido. Ou seja, visa desenvolver o sentimento do amor entre os sexos, baseado na mais nova e poderosa força: a solidariedade fraterna (KOLLONTAI, 2011, p.132-133).

Em sua autobiografia podemos elencar uma série de reflexões em relação a obstáculos e possibilidades de mudança na vida cotidiana das mulheres, tais como: a) Libertando-se das atividades domésticas, as mulheres passarão a dedicar-se às questões da comunidade; b) Os cuidados com os filhos não seriam mais sua função exclusiva, mas uma tarefa a ser compartilhada com seus respectivos companheiros;

c) Nenhuma mãe cairá em preocupação com seus futuros filhos, visto que a Pátria Comunista assegurará a ambos todas as condições para sua sobrevivência; d) A Pátria Comunista também assegurará a educação dos seus filhos, não Ihes negando sua participação em qualquer momento; e) a maternidade poderá ser vivida de modo seguro, com o apoio e o amparo da sociedade, resguardando, sobretudo, o direito das mulheres de não exercê-la. (KOLLONTAI, 1978).

Segundo ela, não é possível falar em progresso da humanidade sem que o tema da libertação das mulheres esteja em pauta. Mas essa libertação não seria produto da luta das mulheres apenas. A construção de "um novo homem" e de uma "nova mulher" seria resultado da superação de valores e condições de exploração estabelecidas no modo de produção capitalista. Contudo, a expressão "a nova mulher", recebeu uma definição bem mais específica na obra de Kollontai.

\section{A nova mulher}

A partir da análise dos valores e costumes que fundamentavam a família, o matrimônio, a sexualidade, a maternidade e tantos outros aspectos da vida social, Kollontai demonstrou o quanto esse quadro social impossibilitava a verdadeira libertação das mulheres.

Ao final do século XIX, com a inserção das mulheres nas fábricas, se observou uma nova fase na dinâmica de produção. Parecia ser o início do processo de libertação das mulheres, com as indústrias tendo seus postos de trabalho também ocupados pela massa feminina. Todavia, as proletárias não foram poupadas, assim como não eram os homens operários, das inúmeras condições de exploração existentes no contexto fabril. Neste momento, processos de tomada de 
consciência de classe e das especificidades femininas vão se desenvolvendo gradativamente a partir da realidade objetiva e da crescente organização da classe trabalhadora por meio de seus sindicatos.

A mulher moderna surge exatamente sob este contexto de exploração da mão de obra feminina nas fábricas. Essa nova e dolorosa realidade atravessada pelas mulheres da classe proletária impulsionou o desenvolvimento de uma nova consciência e o reconhecimento sobre as variadas formas de opressão feminina. Sobre isso, a autora russa afirma:

A mulher moderna, a mulher que denominamos celibatária, é filha do sistema econômico, não como tipo acidental, mas como realidade cotidiana, uma realidade da massa, um fato que se repete de forma determinada, nasceu com o ruído infernal das máquinas da usina e da sirene das fábricas (KOLLONTAI, 2011, p.15).

Como afirmamos anteriormente, a Revolução Russa possibilitou o desenvolvimento de uma nova concepção e relações de gênero que não se resolveram imediatamente com a tomada do poder pelo proletariado organizado. Segundo Kollontai (2011), apesar dos progressos daqueles primeiros anos da Revolução, havia um longo caminho a ser percorrido em relação à superação de valores herdados do passado pré-revolucionário que marcavam a visão de mundo e a memória de todos.

Neste sentido, Alexandra Kollontai acreditava que:

As mulheres do novo tipo, ao criar os valores morais e sexuais, destroem os velhos princípios na alma das mulheres que ainda não se aventuraram a empreender a marcha pelo novo caminho. São estas mulheres do novo tipo que rompem com os dogmas que as escravizam. A influência das mulheres trabalhadoras estende-se muito além dos limites de sua própria existência. As mulheres trabalhadoras contaminam com sua crítica a inteligência de suas contemporâneas, destroem os velhos ídolos e hasteiam o estandarte da insurreição para protestar contra as verdades que as submeteram durante gerações. As mulheres do novo tipo, celibatário e independente, ao se libertarem, libertam o espírito agrilhoado, durante séculos, de outras mulheres ainda submissas (KOLLONTAl, 2011, p. 24).

Porém,

Os sentimentos atávicos perturbam e debilitam as novas sensações. As velhas concepções da vida prendem ainda o espírito da mulher que busca sua libertação. $O$ antigo e o novo se encontram em contínua hostilidade na alma da mulher. [...] têm que lutar contra um 
inimigo que apresenta duas frentes: o mundo exterior e suas próprias tendências, herdadas de suas mães e avós (KOLLONTAI, 2011, p. 25).

A construção do socialismo requer, além das radicais transformações no campo da organização do trabalho e da produção da vida, a promoção de uma nova consciência e psicologia humana. Assim, o "novo homem" e a "nova mulher" representam o novo sentido que Kollontai e tantos outros militantes se dedicaram integralmente a construir naquele primeiro quarto de século $X X$, interrompido pelas mudanças de rumo de direção política após a morte de Lenin em 1926.

\section{Considerações finais}

Os aspectos do pensamento e das lutas de Alexandra Kollontai aqui apresentadas por meio de suas memórias e reflexões é um exercício de aproximação ao pensamento de uma revolucionária que ousou lutar, organizada e coletivamente, pela revolução social, e que se articula ao combate pela superação da opressão contra as mulheres.

A leitura de suas memórias e escritos teóricos nos permitiu adentrar em um universo de questões que articulam o privado e o público no processo de construção de modos de vida e visões de mundo. Neste caso específico, abordamos as ideias e recordações de uma mulher em meio a um processo de transição histórico-social profundamente marcado por mudanças bruscas e estruturais: a Revolução.

Kollontai evidenciou que com a tomada de poder em outubro de 1917, a luta contra a opressão da mulher ganharia outra perspectiva. Apesar das rápidas mudanças na organização da produção e do Estado, havia um longo percurso e barreiras a serem superadas no que se refere ao estabelecimento de relações pessoais e de gênero.

Em relação aos desdobramentos e do sentido das revoluções, Caio Prado Júnior (1966) entende que revolução é mais do que o emprego da força ou a insurgência. O autor afirma que o "seu significado próprio se concentra na transformação, e não no processo imediato através de que se realiza" (1966, p. 1).

Kollontai entendia que o processo de criação do novo homem e da nova mulher não se realizaria por decretos ou ultimatos. Ela tinha plena consciência disso, mas sabia também que essas transformações não se dariam de forma espontânea, 
sem a intervenção da educação, da política estatal, da organização das mulheres comunistas.

Sem dúvida, Alexandra Kollontai nos deixou um legado de muita importância nestes tempos de avanços e recuos da luta contra a opressão da mulher e pela emancipação humana, sobretudo quando observamos e constatamos um aumento no Brasil do número de violência contra a mulher, sobretudo no período de isolamento social por conta da Pandemia de Coronavírus. O Site Uol, em reportagem publicada no dia 20 de abril de 2020, ${ }^{6}$ informou que "No contexto da pandemia de covid-19, os atendimentos da Polícia Militar a mulheres vítimas de violência aumentaram 44,9\% no estado de São Paulo". A reportagem fala ainda do aumento de 19,8\% das denúncias de violência doméstica no estado de São Paulo, desde o decreto de isolamento social adotado pelo governo paulista, o que foi considerado um dado inédito obtido através da Secretaria de Segurança Pública. Com base nos atendimentos realizados pela Polícia Militar entre os dias 20 de março e 13 de abril deste ano, foram 7.933 denúncias contra 6.624 no ano de2019.

Esses dados são indicadores da necessidade da superação dessas relações de opressão contra a mulher e que têm suas bases fundamentais no modo de produção da existência humana organizado pelo sistema privado dos grandes meios de produção. Essa forma de produzir a vida tem levado a humanidade a momentos cada vez mais intensos de barbárie, exploração e opressão, aprofundados por fenômenos como esses que agora vivemos que não é apenas provocado por um vírus letal, mas pela incapacidade do capitalismo responder de modo profundamente solidário e eficiente a essas contingências.

As reflexões de Alexandra Kollontai, articulando a organização política de mulheres e homens pela superação da sociedade burguesa, a luta contra a opressão da mulher e a revolução são atuais e demandam amplos debates e ações nesse momento dramático pelo qual passa a humanidade.

\section{Referências}

BOITO, Misa (Org.). A luta contra a opressão da mulher: recuperando uma abordagem de classe. São Paulo: Editora Nova Palavra, 2016.

6 UOL, SP: violência contra mulher aumenta 44,9\% durante pandemia. Disponível em https://noticias.uol.com.br/ultimas-noticias/agencia-brasil/2020/04/20/sp-violencia-contra-mulher- aumenta449-durante-pandemia.htm?cmpid=copiaecola 
COBRA, Rubem Queiroz. Vida, pensamento e obra de Saint-Simon. Página de Filosofia Contemporânea. Brasília,1999 [<http://www.cobra.pages.nom.br/fmp-saintsimon.html>. Acesso em: 11 jan. 2017.

PRADO JR, Caio. A revolução brasileira. São Paulo: Brasiliense, 1966.

KOLLONTAI, Alexandra. A nova mulher e a moral sexual. São Paulo: Editora Expressão Popular, 2011.

Autobiografía de una mujer emancipada. Barcelona: Ed. Editorial Fontamara, 1978. 